\title{
Cryptococcus in a Wild Loon (Gavia immer)
}

\author{
Mark A. Pokras, BS, DVM ${ }^{1}$, Rose Miconi, BS ${ }^{1}$, Steven Engler, BS, DVM, Dipl. ACVP², \\ Alison Hazel, BS, DVM ${ }^{3}$, Romona Haebler, BS, PhD, Dipl. ACVP4 \\ ${ }^{1}$ Wildife Clinic, Tufts University Cummings School of Veterinary Medicine, North Grafton, Massachusetts \\ 2 Antech Diagnostics, Framingham, Massachusetts \\ ${ }^{3}$ Liverpool Animal Health Center, Liverpool, New York \\ ${ }^{4}$ Us Environmental Protection Agency, Naragansett, Rhode Island
}

\begin{abstract}
A debilitated adult male common loon (Gavia immer) was taken to a veterinary practice in Liverpool, NY where it later died. Subsequently it was sent to Tufts Wildlife Clinic as part of a regional mortality study. During the necropsy, pathology involving most organ systems was noted. Microbiologic and histopathologic examination revealed an overwhelming infection by the fungus Cryptococcus spp.
\end{abstract}

Keywords: loon, Gavia, Cryptococcus, avian, fungal infection

\section{INTRODUCTION}

An adult male common loon (Gavia immer) was observed struggling in the surf and repeatedly beaching itself on the southeast shore of Lake Ontario near Port Ontario, New York. When collected, it appeared weak, ataxic, and had difficulty holding its head upright. After being held and fed overnight, the bird was taken to a local veterinary hospital. There it was given emergency fluids, steroids, and started on a course of enrofloxacin (Baytril ${ }^{\circledR}$, Bayer Corporation,

Mark Pokras is Director of the Wildlife Clinic at Tufts University. He is heavily involved in conservation medicine and continues to inspire veterinary students to follow their hearts and strive to better our world.

Rose Miconi has a BS in wildlife biology from the University of Rhode Island and for many years worked with Dr. Pokras on Ioon conservation issues.

Steven Engler is a veterinary pathologist who taught for many years at Tufts Cummings School of Veterinary Medicine. He currently provides diagnostic pathology services for Antech Diagnostics, Inc.

Alison Hazel worked in upstate New York practicing small animal medicine and providing local rehabilitators with veterinary services. In 1998 she was voted Wildlife Veterinarian of the Year for New York State.

Romona Haebler is a veterinary pathologist at the US EPA's Atlantic Ecology Division, in Rhode Island. Mona has many years of experience studying disease and toxicologic threats to marine mammals, birds, and reptiles.
Shawnee Mission, KS). Survey radiographs revealed rounded densities in several air sacs. The bird died within a few hours.

\section{POST MORTEM EXAMINATION}

The carcass was refrigerated and shipped overnight to Tufts University Cummings School of Veterinary Medicine (TCSVM). Upon arrival, the carcass was weighed, radiographed, and necropsied. The bird weighed $4.2 \mathrm{~kg}(9.26 \mathrm{lb})$, compared to mean weights of healthy loons which were $5.54 \mathrm{~kg}(12.21 \mathrm{lb})$ for males and $4.50 \mathrm{~kg}(9.92 \mathrm{lb})$ for females (Burgess et al 2005). The keel protruded slightly, but was not noticeably prominent. An external examination revealed minor abrasions on both sides of the gape, but no other obvious wounds. An incision was made from the cranial aspect of the keel to the caudal aspect of the abdomen to allow an internal examination. There was a moderate amount of fat present subcutaneously and at the thoracic inlet. Both liver lobes were pale cranially. The spleen was dramatically enlarged (several times normal size), hemorrhagic, and nodular. The right abdominal air sac and many abdominal serosal surfaces exhibited areas that were covered with gelatinous, yellow, nodular structures ranging in size from 1 to $6 \mathrm{~mm}$. A thick, jelly-like, yellowish-brown mass covered the left cranial kidney, testis, and adrenal, and compressed the cranial kidney lobe. The right cranial lobe of the kidney was similarly, but less severely, involved. At necropsy, samples were taken for aerobic bacterial and fungal cultures. Tissue samples were preserved in neutral, buffered 10 percent formalin for histopathologic examination. Liver, kidney, and brain samples were archived at $-80^{\circ} \mathrm{C}\left(-112^{\circ} \mathrm{F}\right)$.

\section{HISTOPATHOLOGY}

Samples of kidney, liver, lung, air sac, heart, spleen, thyroid, thymus, and testis were examined histopatho- 


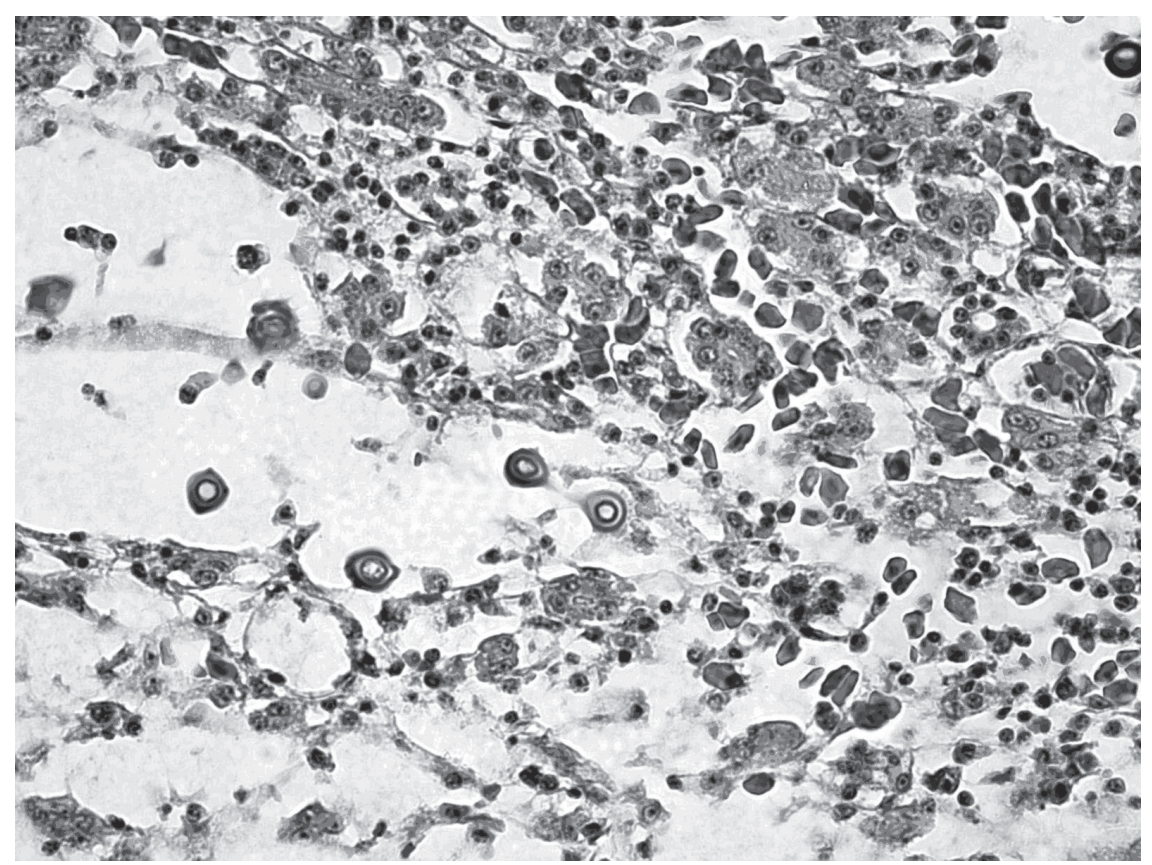

Figure 1a. $40 X$ image of renal parenchyma with severe and diffuse disruption of cellular architecture. Large areas of cellular infiltration into the parenchyma contained both inflammatory cells and yeast organisms consistent with Cryptococcus.

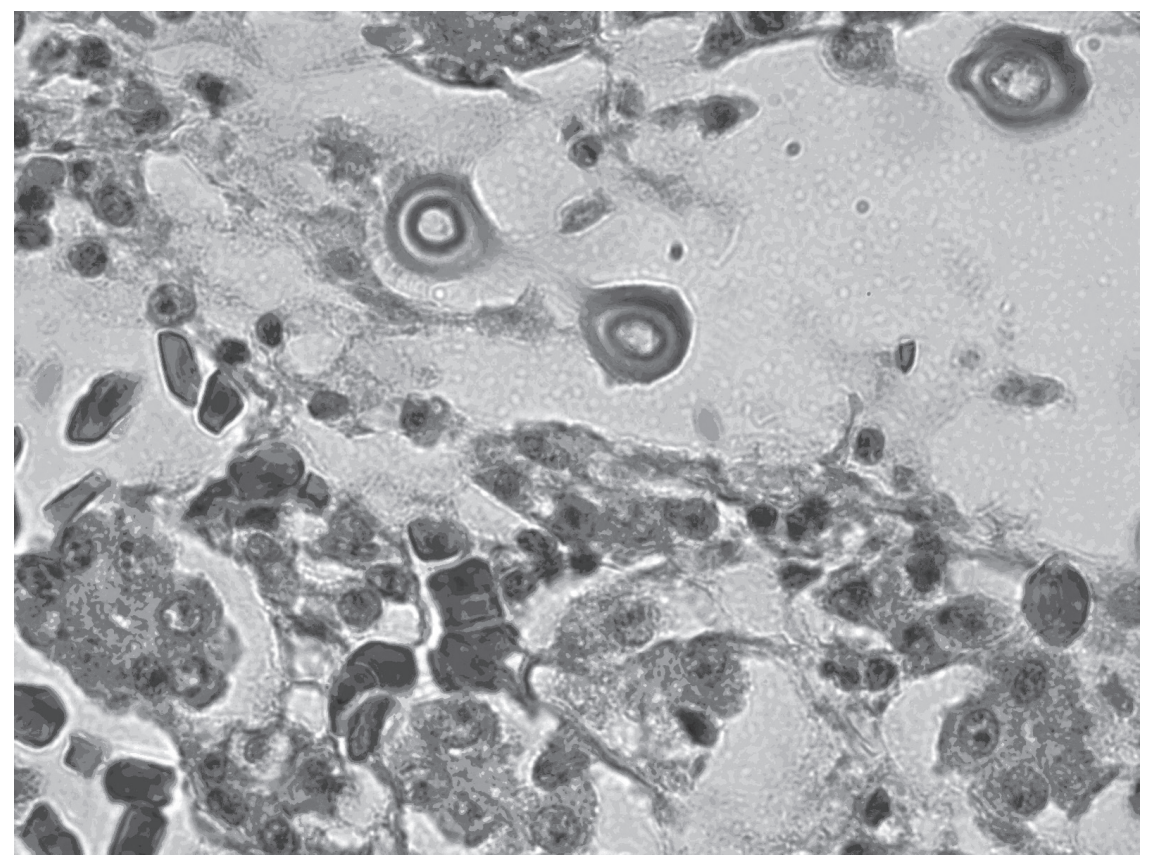

Figure 1b. $100 X$ image of same tissue.

logically. There was severe and diffuse disruption of cellular architecture in kidney (Figures $1 \mathrm{a}$ and $1 \mathrm{~b}$ ), lung, air sac, spleen, and thyroid. Large areas of cellular infiltration into the parenchyma contained both inflammatory cells and yeast organisms morphologically consistent with Cryptococcus. The organisms were 4 to $10 \mu \mathrm{m}$ in diameter, surrounded by a pale, basophilic mucilaginous capsule. Many organisms demonstrated a single, narrow-based bud (Figure 2). The yeast forms frequently could be identified within large foamy macrophages and surrounded by heterophils. Massive numbers of extra-cellular organisms also were present, infiltrating and displacing adjacent tissue parenchyma and filling the air sac lumen. In thyroid (Figure 3), as in kidney and lung, yeast and inflammation deep in the parenchyma caused pressure atrophy of surrounding tissue.

\section{Discussion}

To the authors' knowledge, this is the first reported clinical case of Cryptococcus in an aquatic bird from the wild.

Cryptococcus is an imperfect, saprophytic, encapsulated yeast-like, basidiomycete (or 'club' fungus) that has been documented to cause disease in humans and a wide variety of animals (Chute 1991; Howard 2003). The sexually reproducing form of the fungus (or teleomorph stage) also is known as Filobasidiella neoformans. Humans and animals most commonly affected are individuals that have been housed with birds or those associated with bird feces, dirty conditions, or who are immunosuppressed. Cryptococcus reproduces asexually by budding; cells are spherical and surrounded by thick mucilaginous (sticky, gelatinous) capsules. Cell diameter is 4 to $6 \mu \mathrm{m}$ and the capsule is 1 to $2 \mu \mathrm{m}$ thick. The fungus grows well within 48 hours at $20^{\circ} \mathrm{C}$ on glucose agar (Warren and Hazen 1999). Although there are many species of Cryptococcus, C. neoformans is the species reported most regularly as pathogenic in humans and animals (Jungermann and Schwarzmann 1972). Until recently C. neoformans was described as having three subspecies, C. neoformans v. gattii, v. grubii, and v. neoformans, but Cryptococcus gattii is currently recognized as a separate species based on biochemical and molecular criteria. It has worldwide distribution in temperate and tropical climates and has been isolated from many natural sources including rotting vegetation. This fungus occurs as a free-living, nonparasitic saprophyte in soil (Emmons 1951; Hull 1963; Walter and Atchinson 1966). There 
also is a regular association with the decaying portions of eucalyptus trees (Eucalyptus spp.) and related plants (Kidd et al 2007; Sorrell et al 1996). In many tropical and temperate areas Cryptococcus is isolated frequently from soils enriched with the excreta of pigeons or other birds (Irokanulo et al 1997; Kielstein 2000; Migaki et al 1978; Decostere et al 2003).

Cryptococcus is one of the most common opportunistic pathogens seen in human patients whose immune systems are compromised by AIDS, organ transplantation, and other sources (Howard 2003). Nosanchuk et al (2000) reported the transmission of Cryptococcus neoformans from a pet cockatoo to its immunocompromised owner.

Clinical disease is regularly reported from domestic animals, most frequently cats (Chute 1991; Medleau and Barsanti 1998). Cryptococcus also has been reported in ferrets (Malik et al 2002) and a llama (Bildfell et al 2002). Most cases reported in wildlife have come from captive animals. Cryptococcus neoformans has been reported in an Allen's swamp monkey (Allenopithecus nigrovirdis) (Barry and Stadler 1995) and shown to be the cause of death in cheetahs (Acinonyx jubatus) (Berry et al 1997; Bolton et al 1999), a common anaconda (Eunectes murinus) (McNamara et al 1994), as well as tree shrews (Tupaia tana and Tupaia minor) and elephant shrews (Macroscelides proboscides) (Tell et al 1997), cervids (Aguilar and Hilton 1999; Hamir et al 2002), and koalas (Phasolarctos cinereus) (Krockenberger et al 2003). One case of cryptococcosis in a wild fox was suspected initially of being rabies based on the animal's behavior (Staib et al 1985). Cryptococcosis also has been described in marine mammals (Gales et al 1985; Migaki et al 1978; Miller et al 2002; Stephen et al 2002).

First described in 1894, Cryptococcus neoformans is considered an emerging disease associated variously with international commerce of plants and animals, global climate change, and a worldwide

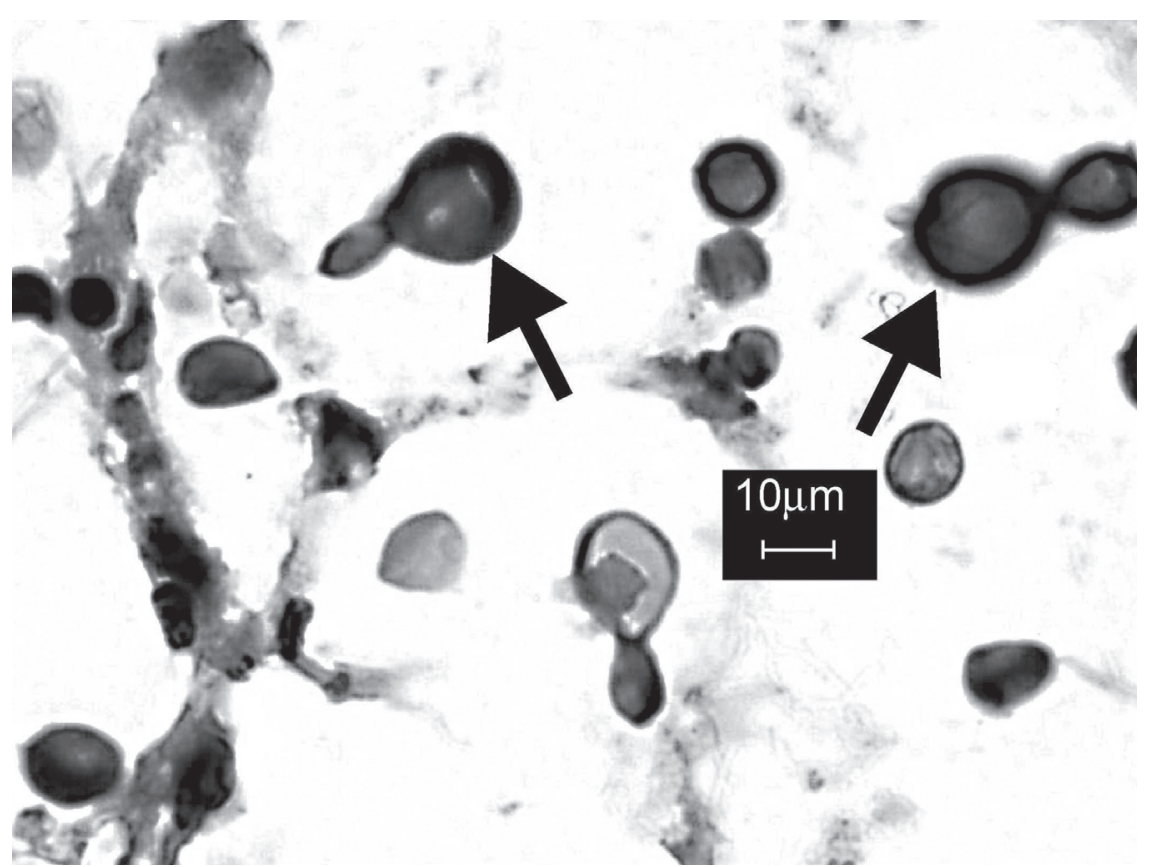

Figure 2. $100 X$ image of lung tissue. The organisms were 4 to $10 \mu \mathrm{m}$ diameter, surrounded by a pale, basophilic mucilaginous capsule, and many demonstrated a single, narrowbased bud.

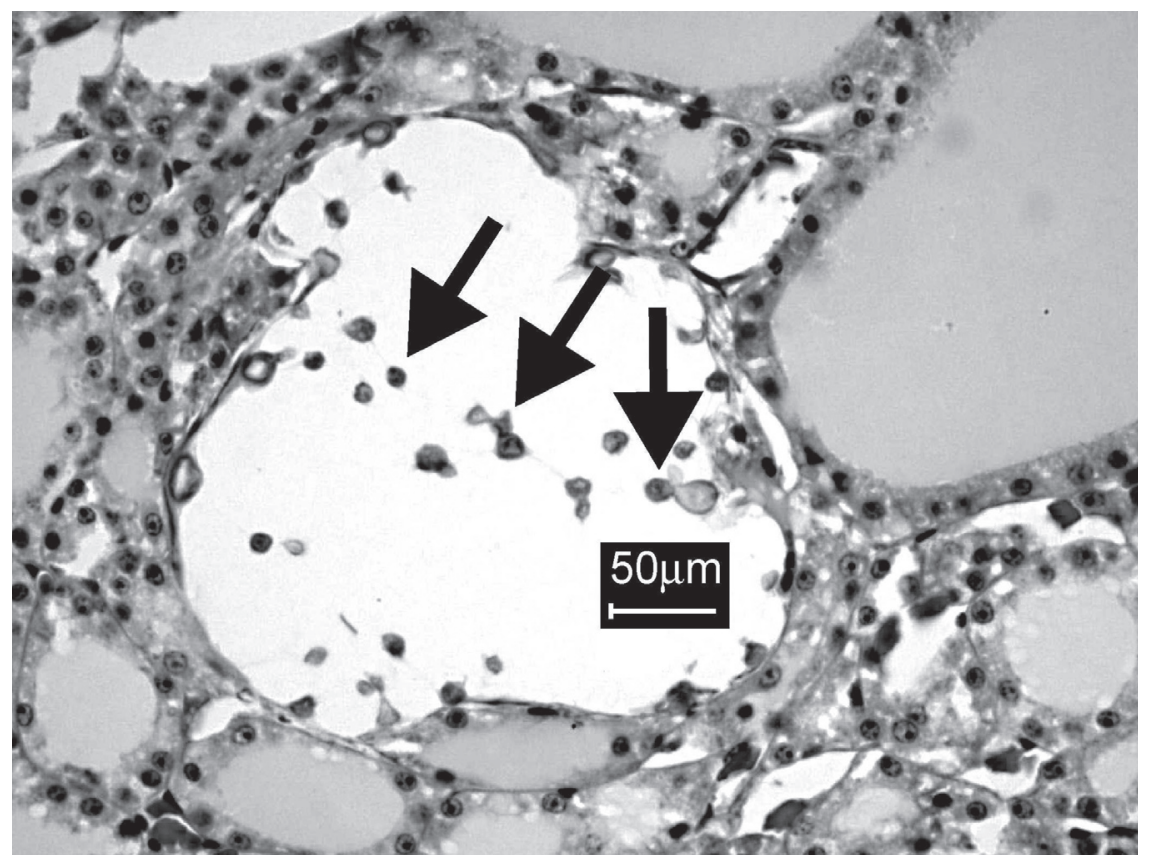

Figure 3. $40 X$ image of thyroid tissue. As in kidney and lung, yeast and inflammation deep in the parenchyma caused pressure atrophy of surrounding tissue. increase in immunosuppressed animals and people (Howard 2003; Simmer and Secko 2008). Since 1999 Vancouver Island, British Columbia, Canada has been the location of a dramatic, multispecies increase in the incidence of clinical cryptococcosis involving over 50 people and a number of llamas, ferrets, marine mammals, and other species (Kidd et al 2007; Stephen et al 2002). In this instance the fungus (Cryptococcus gattii) has not yet been cultured from the 
rotting wood of introduced exotic eucalypts, but has been found associated with a variety of other trees on the island including fir, oak, cedar, maple, and cherry. Recent studies by Kidd et al (2007) document that, in Vancouver, Cryptococcus gattii is becoming more widespread when the spores travel on the feet of humans and animals, on the wheels of vehicles, in woodchips and wood products such as pallets, and also in samples from both fresh and salt water. These investigators documented the spread of the pathogen to mainland British Columbia and into the state of Washington. They speculate that migratory birds also might serve to transport spores widely. Kidd and her colleagues (2007) suggest that Cryptococcus should be seen as a potential threat to the US and Canada and that this pathogen could serve as an excellent model for emerging infectious diseases.

Classically, clinical cryptococcosis often is divided into temperate versus tropical diseases. Temperate cryptococcosis is associated most often with immunosuppressed humans or other animal hosts, whereas the tropical form of the disease often occurs in immunocompetent animals and close contact with eucalyptus trees (Peachey et al 1998; Simmer and Secko 2008). Recent work shows that variation in the pathogenicity of strains of Cryptococcus neoformans may depend on heritable variations in the fungus' polysaccharide capsule, melanin content, and production of soluble metabolites (Buchanan and Murphy 1998; Luberto et al 2003). These variations may have evolved to allow the fungus to defend itself against amoeboid and nematode predators but, once introduced into vertebrate hosts, they may be effective in defense against macrophages and granulocytes, modulate phagocytosis, and increase the fungus' ability to invade tissues (Casadevall et al 2003; Feldmesser et al 2001; Tucker and Casadevall 2002; Wright et al 2002). Given the aquatic nature of loons, the authors speculate that this bird may have been exposed to Cryptococcus from decomposing plant materials in the nest. Because the bird was found on the Great Lakes during fall migration, it is presumed that earlier in the year the bird had nested in southern or central Canada. Loons show a great deal of breeding site fidelity and may rebuild their nest every year from immediately available vegetation (McIntyre 1988). In Saskatchewan, 63 percent of loon nesting material is leaf litter and twigs, as compared to New Hampshire where only 25 percent of the nests contain leaf litter and twigs (McIntyre 1988). Thus, nests possibly could harbor Cryptococcus in the rotting vegetation.

\section{CONCLUSION}

Given the apparent rarity of Cryptococcus in wild birds in North America, it is difficult to know the significance of this particular case. However, the occurrence of an emerging disease in a novel species and an unexpected geographic area is worthy of note.

Global environmental alterations including climate change, habitat destruction, and the anthropogenic spread of exotic species, drug residues, and other pollutants threaten much of Earth's wildlife. Such environmental problems contribute significantly to the emergence of new animal and human diseases. Wildlife rehabilitators can play a significant role in the early detection and subsequent prevention of disease spread. But in doing so, they must also protect their own health.

This case illustrates the usefulness of carrying out post mortem examinations on wildlife that are found dead or that die while undergoing rehabilitation. But the case also illuminates one of the dangers of such examinations-the possibility of encountering a serious human pathogen. The authors wore appropriate protective gear and performed the necropsy in a dedicated necropsy space that was well-equipped and ventilated; many rehabilitators do not have such facilities at hand. Thus, it is important for rehabilitators to work with their veterinarians, state and federal wildlife agencies, and other professionals to investigate suspicious cases or outbreaks. It is also important to remind rehabilitators of the importance of making their findings public by presenting the information at meetings or by publishing case reports such as this one.

\section{LITERATURE CITED}

Aguilar, R. F., and C. D. Hilton. 1999. Clinical Challenge. Osteolysis and Cellulitis Secondary to Cryptococcus neoformans in a Barasingha (Cervus duvaucelii). Journal of Zoo and Wildlife Medicine. 30(4): 591-594.

Barry, M. T., and C. K. Stadler. 1995. Successful Treatment of Cryptococcus neoformans Infection in an Allen's Swamp Monkey (Allenopithecus nigroviridis). Journal of Zoo and Wildlife Medicine. 26(1): 109-114.

Berry, W. L., J. E. Jardine, and I. W. Espie. 1997. Pulmonary Cryptococcoma and Cryptococcal Meningoencephalitis in a King Cheetah (Acinonyx jubatus). Journal of Zoo and Wildlife Medicine. 28(4): 485-490.

Bildfell, R. J., P. Long, and R. J. Sonn. 2002. Cryptococcosis in a Llama (Lama glama). Journal of Veterinary Diagnostic Investigation. 14(4): 337-339. 
Bolton, L. A., R. G. Lobetti, D. N. Evezard, J. A. Picard, J. W. Nesbit, J. Van Heerden, and R. E. Burroughs. 1999. Cryptococcosis in Captive Cheetah (Acinonyx jubatus): Two Cases. Journal of the South African Veterinary Association. 70(1): 35-39.

Buchanan, K. L., and J. W. Murphy. 1998. What Makes Cryptococcus neoformans a Pathogen? Emerging Infectious Disease. 4(1): 71-83.

Burgess, N. M., D. C. Evers, and J. D. Kaplan. 2005. Mercury and Other Contaminants in Common Loons Breeding in Atlantic Canada. Ecotoxicology. 14: 241-252.

Casadevall, A., J. N. Steenbergen, and J. D. Nosanchuk. 2003. "Ready Made" Virulence and "Dual Use" Virulence Factors in Pathogenic Environmental Fungi-Cryptococcus neoformans Paradigm. Current Opinion in Microbiology. 6(4): 332-337.

Chute, H. L. 1991. Miscellaneous fungal infections. Pp. 338-339 in Diseases of Poultry, 9th edition. (B. W. Calnek, H. J. Barnes, C. W. Beard, W. M. Read, and H. J. Yoder, eds.). Iowa State University Press: Ames, IA.

Decostere, A., K. Hermans, T. De Baere, F. Pasmans, and F. Haesebrouck. 2003. First Report on Cryptococcus laurentii Associated with Feather Loss in a Glossy Starling (Lamprotornis chalybaeus). Avian Pathology. 32(3): 309-311.

Emmons, C. W. 1951. Isolation of Cryptococcus neoformans from Soil. Journal of Bacteriology. 62: 685-690.

Feldmesser, M., S. Tucker, and A. Casadevall. 2001. Cryptococcus neoformans: Intracellular or Extracellular? Trends in Microbiology. 9(9): 418.

Gales, N., G. Wallace, and J. Dickson. 1985. Pulmonary Cryptococcosis in a Striped Dolphin (Stenella coeruleoalba). Journal of Wildlife Diseases. 21(4): 443-446.

Hamir, A. N., J. M. Miller, and R. J. Sonn. 2002. Meningoencephalitis and Pneumonia Associated with Cryptococcus neoformans Infection in a Free-ranging Elk in the U.S.A. Veterinary Record. 151(11): 332-334.

Howard, D. 2003. Pathogenic Fungi in Humans and Animals. Marcel Dekker: New York, NY.

Hull, T. G. 1963. Diseases Transmitted from Animals to Man, 5th edition. Pp. 468-470. Charles C. Thomas: Springfield, IL.
Irokanulo, E. O. A., A. Makinde, C. O. Akuesgi, and M. Ekwonu. 1997. Cryptococcus neoformans var. neoformans Isolated from Droppings of Captive Birds in Nigeria. Journal of Wildlife Diseases. 32(2): 343-345.

Jungermann, P. F., and R. M. Schwarzmann. 1972. Veterinary Medical Mycology. Lea \& Febiger: Philadelphia, PA.

Kidd, S. E., P. J. Bach, A. O. Hingston, S. Mak, Y. Chow, L. MacDougall, J. W. Kronstad, and K. H. Bartlett. 2007. Cryptococcus gattii Dispersal Mechanisms, British Columbia, Canada. Emerging Infectious Disease. 13(1): 51-57.

Kielstein, P., H. Hotzel, A. Schmarlreck, D. Khaschabi, and W. Glawischnig. 2000. Occurrence of Cryptococcus spp. in Excreta of Pigeons and Pet Birds. Mycoses. 43(1-2): 7-15.

Krockenberger, M. B., P. J. Canfield, and R. Malik. 2003. Cryptococcus neoformans var. gattii in the Koala (Phasolarctos cinereus): A Review of 43 Cases of Cryptococcosis. Medical Mycology. 41(3): 225234.

Luberto, C., B. Martinez-Mariño, D. Taraskiewicz, B. Bolaños, P. Chitano, D. L. Toffaletti, G. M. Cox, J. R. Perfect, Y. A. Hannun, E. Balish and M. Del Poeta. 2003. Identification of App. 1 as a Regulator of Phagocytosis and Virulence of Cryptococcus neoformans. Journal of Clinical Investigations. 112: 1080-1094.

McIntyre, J. W. 1988. The Common Loon: Spirit of Northern Lakes. University of Minnesota Press: Minneapolis, MN.

McNamara, T. S., R. A. Cook, J. L. Behler, L. Ajello and A. A. Pachye. 1994. Cryptococcosis in a Common Anaconda (Eunectes murinus). Journal of Zoo and Wildlife Medicine. 25(1): 128-132.

Malik, R., M. B. Krockenberger, G. Cross, R. Doneley, D. N. Madill, D. Black, P. McWhirter, A. Rozenwax, K. Rose, M. Alley, D. Forshaw, I. Russell-Brown, A. C. Johnstone, P. Martin, C. R. O'Brien, and D. N. Love. 2003. Avian Cryptococcosis. Medical Mycology. 41(2): 115-124.

Malik, R., B. Nalderton, D. Finaison, M. B. Krockenberger, H. Karaoglu, W. Meyer, P. Martin, M. P. France, J. McGill, S. J. Lester, C. R. O'Brien, and D. N. Love. 2002. Cryptococcosis in Ferrets: A Diverse Spectrum of Clinical Disease. Australian Veterinary Journal. 80(12): 749-755.

Medleau, L., and J. A. Barsanti. 1998. Cryptococcus. Pp. 383-390 in Infectious Diseases of the Dog and Cat, 2nd edition. (C. E. Greene, ed.). W. B. Saunders Co: Philadelphia, PA. 
Migaki, G., R. D. Gunnels, and H. W. Casey. 1978. Pulmonary Cryptococcosis in an Atlantic Bottlenosed Dolphin (Tursiops truncatus). Laboratory Animal Science. 28(5): 603-606.

Miller, W. G., A. A. Padhye, W. Van Bonn, L. Jensen, M. E. Brandt, and S. H. Ridgway. 2002. Cryptococcosis in a Bottlenose Dolphin (Tursiops truncatus) Caused by Cryptococcus neoformans var. gattii. Journal of Clinical Microbiology. 40(2): 721-724.

Nosanchuk, J. D., S. Shoham, B. C. Fries, D. S. Shapiro, S. M. Levitz, and A. Casadevall. 2000. Evidence of Zoonotic Transmission of Cryptococcus neoformans from a Pet Cockatoo to an Immunocompromised Patient. Annals of Internal Medicine. 132(3): 205-208.

Peachey, P. R., P. O. Gubbins, and R. E. Martin. 1998. The Association Between Cryptococcal Variety and Immunocompetent and Immunocompromised Hosts. Pharmacotherapy. 18(2): 255-264.

Simmer, M., and D. M. Secko. 2008. A Peach of a Pathogen: Cryptococcus neoformans. Available at: <http://www.scq.ubc.ca/a-peach-of-a-pathogencryptococcus-neoformans/> [cited 2008 October 15].

Sorrell, T. C., A. G. Brownlee, P. Ruma, P. Malik, T. J. Pfeiffer, and D. H. Ellis. 1996. Natural Environmental Sources of Cryptococcus neoformans var. gattii. Journal of Clinical Microbiology. 34(5): 1261-1263.

Staib, F., W. Weller, S. Brem, R. Schindlmayer, and E. Schmittdiel. 1985. A Cryptococcus neoformans Strain from the Brain of a Wildlife Fox (Vulpes vulpes) Suspected of Rabies: Mycological Observations and Comments. Zentralblatt Fuer Bakteriologie Mikrobiologie Und Hygiene (Reihe A). 260(4): 566-571.

Stephen, C., L. Lester, W. Black, M. Fyfe, and S. Raverty. 2002. Multispecies Outbreak of Cryptococcosis on Southern Vancouver Island, British Columbia. Canadian Veterinary Journal. 43(10): 792-794.

Tell, L. A., D. K. Nichols, W. P. Flemming, and M. Bush. 1997. Cryptococcosis in Tree Shrews (Tupaia tana and Tupaia minor) and Elephant Shrews (Macroscelides proboscides). Journal of Zoo and Wildlife Medicine. 28(2): 175-181.
Tucker, S. C., and A. Casadevall. 2002. Replication of Cryptococcus neoformans in Macrophages is Accompanied by Phagosomal Permeabilization and Accumulation of Vesicles Containing Polysaccharide in the Cytoplasm. Proceedings of the National Academy of Sciences. 99(5): 3165-3170.

Walter, J. E., and R. W. Atchinson. 1966.

Epidemiological and Immunological Studies of Cryptococcus neoformans. Journal of Bacteriology. 92(1): 82-87.

Warren, N. G., and K. C. Hazen. 1999. Candida, Cryptococcus and Morphology of the Fungi. Pp. 1167-1183 in Manual of Clinical Microbiology, 4th edition. (E. J. Baron, M. A. Pfaller, F. C. Tenover, and R. H. Yolken, eds.). American Society for Microbiology: Washington, D.C.

Wright, L., W. Bubb, J. Davidson, R. Santangelo, M. Krockenberger, U. Himmelreich, and T. Sorrell. 2002. Metabolites Released by Cryptococcus neoformans var. neoformans and var. gattii Differentially Affect Human Neutrophil Function. Microbes and Infections. 4(14): 1427-1438. (沺)

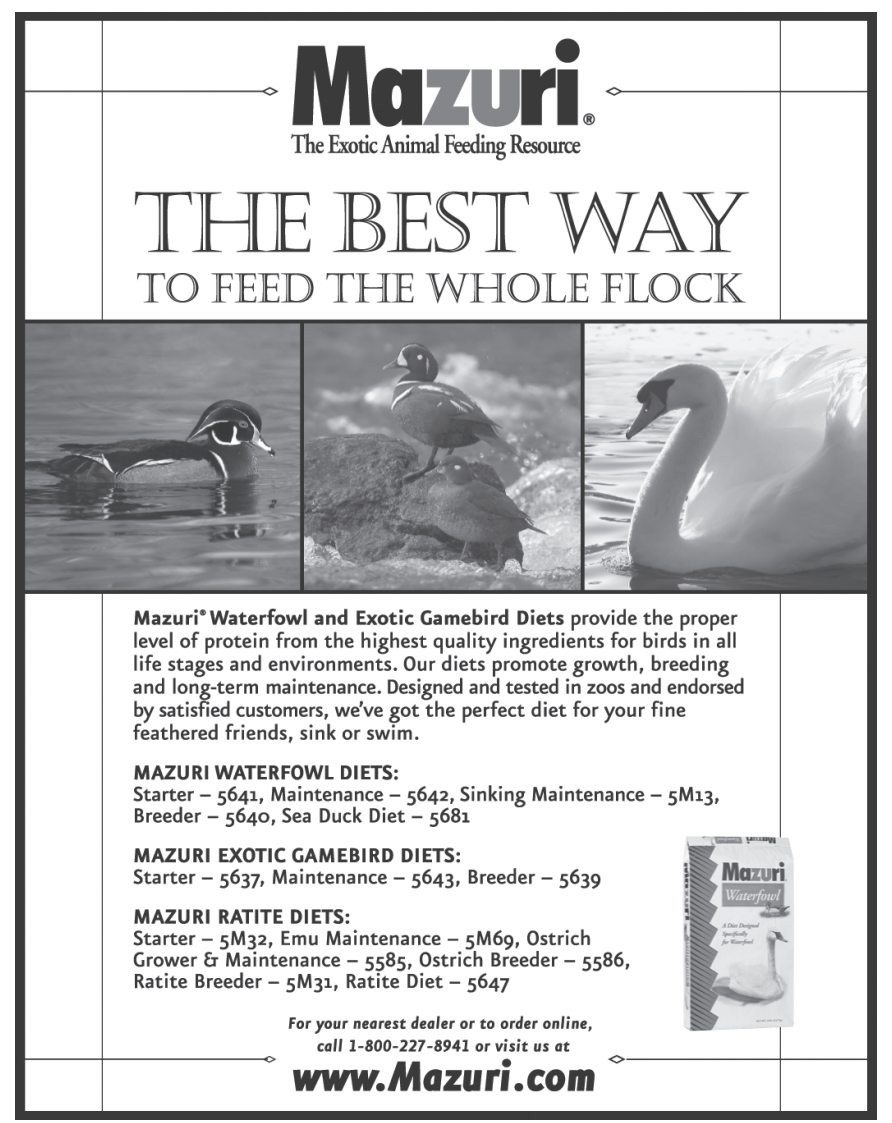

